\title{
O clima organizacional nas bibliotecas universitárias: um estudo das bibliotecas setoriais da Universidade Federal de Pernambuco
}

\author{
Andréa Maria da Silva \\ Alexander Willian Azevedo \\ Fabio Assis Pinho \\ Universidad Federal de Pernambuco - UFPE, Brasil.
}

CASE REPORTS

\begin{abstract}
Resumo
Objetivo. O presente estudo buscou analisar as percepções do clima organizacional dos colaboradores que atuam nas bibliotecas setoriais da Universidade Federal de Pernambuco, em relação à liderança, comunicação, motivação e trabalho em equipe.

Método. Para alcançar o objetivo proposto foi realizada uma pesquisa com aplicação de questionário, sendo respondidas por quarenta colaboradores, vislumbrando obter informações sobre o clima organizacional vivenciado nas bibliotecas setoriais.

Resultados. Os principais resultados da pesquisa apontaram para um clima organizacional predominantemente satisfatório nas bibliotecas analisadas, considerando que a atmosfera organizacional mostrou-se sadia, com líderes entrosados com suas equipes, abertos ao diálogo, com profissionais propícios a exercerem um trabalho com competência.

Conclusões. Compreende-se que o estudo sobre clima organizacional em bibliotecas universitárias é de suma importência, tendo em vista as bibliotecas são organizações vivas, sociais e atuantes constituídas por recursos humanos, tecnológicos, materiais, financeiros, que juntos, necessitam desempenhar com excelência o clima organizacional.
\end{abstract}

Palavras-chave

Clima organizacional; Organizações; Colaboradores; Bibliotecas universitárias

The organizational climate in university libraries: a study of sectoral libraries of the Federal University of Pernambuco

\begin{abstract}
Objective. This study investigates the perceptions of organizational climate of the employees working in the sector libraries at the Federal University of Pernambuco, in relation to leadership, communication, motivation and teamwork.

Method. To achieve the proposed objective a survey was conducted with a questionnaire being answered by forty employees, viewing information on the organizational climate experienced in the sector libraries.

Results. The main results of the survey indicated a predominantly satisfactory organizational climate in the analyzed libraries, considering that the organizational atmosphere proved to be sound, mingled with leaders and their teams, open to dialogue with professionals conducive to exercise a job competently.

Conclusions. It is understood that the study of organizational climate in academic libraries is of paramount importência in order libraries are living, social and active organizations composed of human, technological, material, financial, which together need to perform with excellence the organizational climate.
\end{abstract}

Keywords

Organizational climate; Organizations; Employees, University libraries 


\section{Introdução}

Nos dias atuais, as organizações estão investindo cada vez mais na gestão de pessoas, como uma alternativa eficaz para dinamizar e atender as fortes demandas do mercado. Sabe-se que mercado de trabalho moderno, em nível nacional e internacional, encontra-se gradativamente competitivo, pois nota-se uma concorrência acirrada nos diversos segmentos de atuação existentes, deixando em evidência que profissionais qualificados, empenhados e satisfeitos no trabalho, além de se destacarem, contribuem para o desenvolvimento das organizações.

Tomando por base estas questões, as organizações são impulsionadas a adotarem estratégias que visem à satisfação dos funcionários. E para conhecer a percepção dos mesmos em relação ao ambiente no qual estão inseridos, é pertinente a realização de pesquisas de clima organizacional.

A pesquisa de clima organizacional é um mecanismo utilizado estrategicamente por gestores, no sentido de coletarem as opiniões de suas equipes, identificando se estão satisfeitas ou insatisfeitas com a liderança, comunicação, motivação, trabalho em equipe e outros aspectos que possam influenciar positivamente ou negativamente o desenvolvimento de suas atividades profissionais.

Por sua vez, as bibliotecas universitárias são organizações criadas com a finalidade de democratizar o acesso à informação, no objetivo de fomentar o conhecimento e contribuir com a produção e formação acadêmica de discentes, docentes e pesquisadores. Os funcionários que atuam em suas dependências merecem notada atenção, por ser o capital intelectual que dão funcionalidade às atividades desenvolvidas, colaborando para que propósitos estabelecidos sejam concretizados.

Neste sentido, a pesquisa de clima organizacional é uma estratégia viável e diferenciada que os gestores das bibliotecas universitárias podem adotar vislumbrando propiciar um ambiente de trabalho aprazível, a partir de ações de melhorias contínuas para que os funcionários se sintam satisfeitos e atuarem com o melhor desempenho possível.

\section{As organizações e a gestão de pessoas}

As organizações não funcionam de modo independente, pois são organismos vivos, sociais e atuantes que operam através de pessoas, seres pensantes e produtivos, que as levam ao alcance de objetivos e metas organizacionais. Estas instituições necessitam de pessoas para se manterem no mercado de trabalho e consequentemente, devem conhecê-las e geri-las da melhor forma possível, buscando manter o bom desempenho profissional (SILVEIRA, 2009).

Entende-se por organizações às instituições alocadas na sociedade com a responsabilidade de produzirem produtos e serviços em diversos setores. Ao se inserirem no mercado demarcam estrategicamente suas áreas de atuação, o público que focaliza e os objetivos organizacionais que almejam alcançar (CHIAVENATO, 2010).

Historicamente, a partir da revolução industrial que iniciou na Inglaterra em meados do século XVIII, verificou-se um ímpeto no segmento industrial e no comércio, máquinas foram criadas na intenção de facilitar as atividades de produção das fábricas, intensificando a divisão do trabalho e o mecanicismo. As pessoas eram vistas apenas como recursos de produção, máquinas, seres que não pensavam e só produziam, sem valorização profissional. As organizações não se preocupavam com o bem estar das pessoas, com os benefícios. Isto poderia ser visivelmente percebido na era industrial (FALCÃO, 2010).

Após este período, as organizações vêm passando por notáveis transformações para atingirem seus objetivos e atenderem às expectativas de seu público alvo, além de investirem em ferramentas tecnológicas para otimização de seus serviços, tem priorizado a gestão pessoas para uma atuação mais eficiente e duradoura. (FELDHAUS, 2005). Logo, as organizações planejam, inovam, atribuem responsabilidades aos funcionários e procuram propiciar um ambiente de trabalho agradável para que possam se sentir satisfeito, atuando com comprometimento nos propósitos da organização.

Gil $(2001$, p. 17) conceitua gestão de pessoas como "[...] a função gerencial que visa à cooperação das pessoas que atuam nas organizações, para o alcance dos objetivos tanto organizacionais quanto individuais".

É certo que os seres humanos, por sua natureza, se diferem em personalidade e comportamento. Em vista disso, a área de gestão de pessoas deve estar preparada para enfrentar o grande desafio de coordená-las. É 
incontestável que as organizações esperam resultados de seus quadros de funcionários, e que estes também ambicionam reconhecimento e benefícios pelo seu emprenho (SOTO, 2002).

Nesta acepção, Chiavenato (2010) reflete que as organizações dependem da atuação e dos esforços coletivos de muitas pessoas que colaboram para o sucesso organizacional, e que essa atuação deve ser encarada como uma parceria, uma troca de benefícios entre organização/liderados.

Segundo Macedo (2007) existe uma expectativa das organizações em relação ao seu quadro de funcionário, em familiarizar-se com: missão organizacional, visão de futuro da organização, cliente, metas e resultados, melhorar o desenvolvimento contínuo, trabalho participativo da equipe, comprometimento, dedicação, talento, competências, aprendizado, ética e responsabilidade.

Em contrapartida, dentre as expectativas que os colaboradores nutrem em relação às organizações, estão: oportunidades de crescimento, reconhecimento e recompensas, participação nas decisões, um excelente lugar para trabalhar, camaradagem e coleguismo, alegria e satisfação, boa qualidade de vida no trabalho, apoio e outras (CHIAVENATO, 2010).

Neste prisma, compreende-se que propiciar um ambiente de trabalho agradável é uma estratégia eficiente que as organizações podem realizar na busca de resultados positivos e no atendimento de suas expectativas.

\section{Estrutura e cultura organizacional: conceitos e propostas}

No domínio organizacional, as pessoas vêm recebendo assinalada importância, por serem produtivas e constituídas de talentos, experiências e conhecimentos que são essenciais para o crescimento das organizações. Todas as pessoas que se inserem nesses ambientes possuem competências próprias e são direcionadas para áreas ou setores específicos, nos quais lhe são atribuídas responsabilidades e tarefas (MACEDO, 2009).

$\mathrm{Na}$ esfera organizacional a estipulação de funções, responsabilidades, divisão de setores e tarefas, se sustenta na conveniência de assegurar a eficiência e eficácia nas organizações, considerando que ser eficiente é saber utilizar devidamente os recursos, eliminar desperdícios e ser produtivo, e a eficácia com a capacidade de cumprir objetivos designados (FELDHAUS, 2013).

Todas as organizações, independentemente de seu porte, segmento de atuação e dos produtos e serviços que fornecem, possuem uma cultura organizacional formal ou informal. Culturalmente existem organizações que podem ser rígidas, flexíveis, conservadoras, inovadoras, participativas e possuir outras particularidades, cda uma direciona o seu perfil de acordo com a missão que propõe a oferecer aos clientes e com os objetivos que deseja alcançar, tendo um propósito de existência (CARVALHO, 2011).

De acordo com Luz (2012) cultura organizacional é o conjunto de crenças, valores, costumes, rituais, slogans, mitos, tabus, tradições, sentimentos e comportamentos, compartilhados pelos membros de uma organização. Assim, a cultura organizacional é entendida como a postura que cada organização adota e os valores que advoga almejando alcançar objetivos, diferenciar-se das demais e garantir posição de destaque no mercado.

A cultura organizacional estabelece o estilo de gestão, o processo decisório e de comunicação, incidindo na motivação, na satisfação dos membros envolvidos, influenciando seus comportamentos nas organizações. Ela impacta diretamente o cotidiano dessas instituições e até o padrão arquitetônico de suas instalações, a maneira como os indivíduos se veste, a forma cordial ou informal de tratar parceiros ou clientes podem ser reflexos de sua ampla influência (FALCÃO, 2010).

Segundo Feldhaus (2013) a cultura organizacional é capaz determinar as ações das organizações que possui sua própria identidade, o que pode torná-las um excelente local para trabalhar, ou até mesmo, um ambiente de difícil adaptação.

Ressalta-se que a maneira como a cultura é percebida pode implicar no clima da organização, proporcionando aos colaboradores o sentimento de satisfação ou insatisfação, sendo este último, o causador da desmotivação, da baixa produtividade, ausência de comprometimento e de contentamento com a instituição. 


\section{Clima organizacional em unidade de informação}

No mundo globalizado, abundantemente se fala em diferencial competitivo e como fator permissivo para que as organizações sejam bem sucedidas, salienta-se o desempenho das pessoas que operam nestes espaços.

As instituições que investem em seus funcionários tendem a ter um diferencial em relação a sua concorrência, pois prezam pela qualidade da prestação de seus produtos e serviços, além de estarem em constante processo de mudanças positivas, com geração de novos empreendimentos (RIBEIRO, 2004).

Em pleno século XXI, diversos gestores de organizações mostram um despertar no interesse de fornecer aos funcionários as melhores condições de trabalho admissíveis, com o estímulo ao desenvolvimento profissional, motivação, bem estar, conexão de equipes, aspirando com isso alcançar resultados benéficos. Tendo em vista que as organizações, em sua profundeza, são administradas e compostas por pessoas (SOTO, 2002).

Ao ingressar nas organizações para trabalhar, os indivíduos criam expectativas em satisfazer suas necessidades pessoais e se realizarem profissionalmente. Contudo, nem sempre esses objetivos podem ser alcançados, considerando que existem diversos fatores que norteiam as relações de trabalho e que podem ser vistos não só como positivos, mas também como negativos, causando insatisfação e descontentamento.

O clima organizacional pode ser compreendido como um indicador de satisfação ou insatisfação dos funcionários de uma determinada organização, podendo ser em relação à cultura, a estrutura organizacional, ao processo de comunicação, valorização profissional e a outros aspectos que possam intervir direta ou indiretamente nas atividades e no bem estar junto à organização (CARVALHO, 2011).

Silva (2003, p. 60) expõe que no Brasil o estudo de clima organizacional teve início no ano de 1974 com um trabalho intitulado: "Atmosfera organizacional e o bem-estar psíquico dos contribuintes individuais" desenvolvido pelo psicólogo Arthur Saldanha, que alertava sobre a importância do bem-estar psíquico dos indivíduos nas organizações.

Na visão de Chiavenato (2004) o clima organizacional é a imagem que os funcionários absorvem sobre a organização e se vale da interpretação pessoal que cada colaborador faz em relação às normas, às hierarquias, a conduta, aos costumes e a cultura da organização em sua essência.

A pesquisa de clima organizacional é o instrumento prático utilizado na identificação e avaliação dos padrões de comportamento, atitudes e sentimentos, expostos pelos funcionários das organizações. Coda (1997, p. 99) a considera como: "[...] um levantamento de opiniões que caracteriza uma representação da realidade organizacional consistente, uma vez que retrata o que as pessoas acreditam estar acontecendo em determinado momento na organização". Sendo geralmente realizada sob a forma de entrevistas, questionários ou painéis de debates.

No ato da pesquisa é viável que os entrevistados não necessitem se identificar para que sintam a máxima liberdade e confiança para respondê-la. Quando desenvolvida com sucesso e os resultados devidamente avaliados, a pesquisa de clima trará melhorias no ambiente de trabalho apontando as fraquezas de uma gestão ineficiente e os pontos positivos de uma gestão competente, que preza pela participação dos membros envolvidos com a organização (CARVALHO, 2011).

Em virtude das expectativas geradas, a realização da pesquisa só deve efetuar-se quando os gestores estiverem convictos de que existirão condições para dar respostas aos problemas identificados, sem mascarálos. E para que tenha um sentido realmente plausível, é preciso que seja planejada a ponto de envolver confiabilidade, periodicidade e mudanças necessárias.

\section{Variáveis que influenciam o clima organizacional}

O clima organizacional de qualquer organização pode ser percebido positivamente ou negativamente, dependendo do conjunto de variáveis que dão sustentabilidade e viabilidade ao trabalho dos profissionais.

Entre as diversas variáveis, ou seja, elementos que influenciam e fazem parte do cotidiano das organizações, serão brevemente destacadas: a liderança, comunicação, motivação e trabalho em equipe no âmbito organizacional (SILVA, 2013). 
A liderança nas organizações corresponde ao processo de coordenação de pessoas, com o objetivo de influenciá-las a contribuírem com o alcance de objetivos designados.

Para Maximiano (1997, p. 156) a "[...] liderança é a capacidade pessoal de aglutinar pessoas para a realização de objetivos", ou seja, pode ser vista como o processo de conduzir as ações ou influenciar o comportamento e a mentalidade de outras pessoas.

O líder deve possuir habilidade para influenciar pessoas no ambiente de trabalho, entre elas: boa articulação com os membros, visão holística para tomar decisões e equilíbrio para driblar os diferentes problemas que possam surgir em uma equipe de trabalho (CHIAVENATO, 2004).

Já a comunicação é uma atividade indispensável para a sustentabilidade das organizações. Para Feldhaus (2005) a comunicação organizacional é o processo da circulação da informação que desempenha um papel importante na forma pela qual a informação é compartilhada e utilizada. A internet, intranet, e-mail, vídeo conferência, entre outras, são exemplos da explosão das tecnologias de comunicação.

Diante disto, a falta de comunicação nas organizações pode deixar os funcionários sem as devidas condições para exercerem um trabalho competente, até mesmo sem o direito à participação, à informação e ao bom diálogo com os próprios colegas de trabalho, ocasionando conflitos, mal entendidos, estresses e outras situações desfavoráveis, incidindo para um clima organizacional ruim (CHIAVENATO, 2004).

Por isso, os líderes devem criar condições para que todos os funcionários se mantenham bem informados nas organizações, explorando os diversos meios de comunicação existentes e exercendo uma liderança mais participativa.

A motivação relaciona-se com aquilo que o indivíduo conhece de si mesmo ou do ambiente ao qual está inserido. Nas organizações, trata-se das experiências vivenciadas pelos funcionários e que podem ser motivo de satisfação ou de insatisfação (LUZ, 2012).

As organizações modernas, cada vez mais, estão em busca de profissionais motivados e empenhados no exercício de sua profissão. No entanto, isto tem sido um desafio é por isso que muitas se voltam aos estudos das percepções dos funcionários para identificar os fatores que os desmotivam e o que precisa ser melhorado para mudar esta realidade (SILVA, 2003).

Muitos são os fatores que podem desmotivar funcionários, dentre eles: salários baixos, lideranças autocráticas, falta de reconhecimento e crescimento profissional, conflitos entre equipes de trabalho e outros. Fatores estes que podem comprometer negativamente o clima organizacional de qualquer instituição, colocando em evidência que ele necessita ser mais investigado (RIBEIRO, 2004).

Em virtude da amplitude e diversidade das atividades desenvolvidas pelas organizações, sejam as de pequeno, médio ou grande porte é conclusivo que uma pessoa trabalhando individualmente para realizar tarefas, solucionar problemas, ter contato com o público e desenvolver outras ações, exigiria um esforço exaustivo. Seguramente as atividades levariam um período maior para se concretizarem (CHIAVENATO, 2010).

Assim, o trabalho em equipe surge como uma solução para que pessoas se unam nas organizações, troquem experiências, tenham as atividades distribuídas de forma cooperativa, para atingir metas e objetivos mais rapidamente. Todavia, trabalhar em equipe nem sempre é uma tarefa fácil, uma vez que cada indivíduo tem suas próprias concepções, seus métodos de trabalhos, seus hábitos e costumes e em certas situações é preciso estar em constante consenso, para não haver conflitos (LUZ, 2012).

Partindo disso, a liderança das organizações deve estimular este tipo de trabalho, com maturidade para que as tarefas sejam distribuídas igualitariamente e para que as equipes se mantenham integradas, se comuniquem e estejam unidas em propósitos comuns, para que este fator não comprometa o clima e a harmonia entre os colaboradores.

\section{A biblioteca universitária como organização: enfoque nos funcionários}

A biblioteca universitária é uma organização que tem o objetivo de democratizar a informação, através da disponibilização de produtos e serviços de informação aos usuários, fornecendo suporte para as atividades de ensino, pesquisa e extensão. Ela envolve recursos humanos, tecnológicos, materiais e financeiros, o que reafirma sua posição no mercado como uma organização. 
Para Prado e Abreu (2005, p. 108) "[...] às bibliotecas universitárias, especificamente, compete fornecer informações em níveis compatíveis com as necessidades dos usuários, como apoio imprescindível às atividades de ensino, pesquisa e extensão".

$\mathrm{Na}$ visão de Ribeiro (2004) a biblioteca universitária tem como objetivo satisfazer as necessidades informacionais de seus usuários, através de seu acervo atualizado, que ofereçam serviços e produtos levando em conta a segmentação de clientes (alunos de graduação e pós-graduação, professores, funcionários e pesquisadores) e que nesses serviços e produtos ocorram mudanças e inovações.

Gondim e Siqueira (2004) apud Feldhaus (2005, p. 15) são enfáticos ao dizer que "[...] a biblioteca universitária é o âmago da casa de Ensino Superior, por isso o ambiente em que se instala não pode significar somente o aspecto físico, estrutural e organizacional, mas também as condições ambientais de trabalho".

No entanto, a biblioteca universitária necessita atentar para a inovação, atualização e qualidade dos produtos e serviços prestados, para apoiar satisfatoriamente as atividades acadêmicas e sociais desenvolvidas pela universidade (PRADO, 2005).

É indispensável que a biblioteca universitária, enquanto organização, adote em sua gestão a valorização dos profissionais. Uma vez que estes preconizam seu funcionamento, pois recursos tecnológicos, materiais, financeiros, disponibilização de acervos, catalogação de itens, atendimento aos usuários e outras atividades intrínsecas à área de biblioteconomia, jamais teriam funcionalidade se não existissem pessoas com competências para executá-las (RIBEIRO, 2004).

A avaliação do clima organizacional é uma valiosa ferramenta de diagnóstico para gerir mudanças, em busca de se alcançar maior eficiência nas bibliotecas, um pré-requisito no mundo de hoje (PRADO, 2005).

Assim, a pesquisa de clima organizacional é um mecanismo pertinente que as bibliotecas universitárias podem utilizar, visualizando a participação mais efetiva de seus funcionários.

Visto que, estimular um ambiente de trabalho agradável, através de uma equipe de funcionários motivados e devidamente suscetíveis a exercerem as atividades que lhe forem cabíveis é um grande diferencial para que as bibliotecas obtenham sucesso, atinjam seus objetivos e satisfaçam o público a que atendem (PRADO, 2005).

\section{Procedimentos metodológicos}

O método empregado neste estudo correspondeu à pesquisa quantitativa, em que primeiramente realizou-se um levantamento bibliográfico em livros, artigos científicos e teses e dissertações disponibilizadas nas bases de dados, entre elas: (a) Base de Dados Referenciais de Artigos de Periódicos em Ciência da Informação (BRAPCI), (b) Scientific Electronic Library On line (SCIELO); (c) Biblioteca Digital Brasileira de Teses e Dissertações (BDTD), para maior aprofundamento teórico sobre o assunto. Posteriormente foi realizada uma pesquisa de campo, com aplicação de questionários direcionados a amostra estudada.

Para compor a amostra, foram selecionadas duas bibliotecas setoriais situadas no campus Recife da Universidade Federal de Pernambuco (UFPE), equivalendo respectivamente as bibliotecas setoriais do Centro Tecnologia e Geociência (CTG) e do Centro de Educação (CE).

\section{Instrumento de coleta e análise dos dados sobre clima organizacional}

Um questionário é um instrumento de coleta de dados que pode ser aplicado em pesquisas de campo, sendo representado através de perguntas que devem ser simples e concisas, para que os respondentes entendam com clareza o que está sendo indagado.

Segundo Martins (2006, p. 36),

[...] um questionário é um importante e popular instrumento de coleta de dados para uma pesquisa social. Constitui-se de uma lista ordenada de perguntas que são encaminhadas para potenciais informantes, selecionados previamente. O questionário tem que ser respondido, geralmente, sem a presença do pesquisador.

Luz (2012, p. 39-41) enfatiza a existência de fundamentalmente três tipos de técnicas para pesquisa de clima organizacional: (1) questionário, (2) entrevista e (3) painel de debates. 
O questionário, segundo o autor, é a técnica mais apropriada e utilizada em pesquisas de clima organizacional, pelo fato de ter um custo financeiro relativamente baixo, por preservar o anonimato e permitir que as opiniões dos entrevistados sejam expressas sem maiores receios.

Já a entrevista, que também pode ser aplicada em pesquisas sobre clima organizacional, e, sobretudo sem gastos financeiros, apresenta alguns pontos negativos quanto a sua execução. Esta técnica requer um tempo maior para ser aplicada, exigindo pessoas aptas para conduzi-la de modo a não haver manipulações e falhas nas interpretações.

Além disso, evidencia-se nesta técnica a quebra do anonimato, porque o entrevistado tem contato presencial com o entrevistador, podendo ficar receoso e constrangido para falar abertamente dos assuntos que lhe forem questionados.

Outra técnica empregada é o painel de debates, que se refere a um tipo de pesquisa especial, formulada com a presença de um entrevistador e vários entrevistados reunidos. Cada funcionário vai explanando suas opiniões, seus pontos de vista quanto ao ambiente em que atuam e estimulando seus colegas a contribuirem. Contudo, assim como na entrevista, esta técnica não preza pelo sigilo dos entrevistados e pode deixá-los introspectivos em certos momentos.

Com isso, cabe ao gestor ou gestores responsáveis pela pesquisa de clima organizacional, analisar as técnicas que podem ser aplicadas e verificar qual a melhor opção para coletar as informações de que necessita.

Diante dos benefícios registrados em relação ao questionário, este foi o instrumento adotado para a realização da presente pesquisa de campo. As perguntas foram fechadas e abertas, totalizando dezesseis (16) questões, que abrangeram as seguintes variáveis em torno do ambiente de trabalho das bibliotecas estudadas: liderança, comunicação, motivação e trabalho em equipe.

\section{Discussão dos resultados}

O questionário aplicado foi dividido em cinco seções, sendo representadas da seguinte forma: (1) Perfil dos respondentes, (2) aspecto liderança, (3) aspecto comunicação, (4) aspecto motivação, e (5) aspecto trabalho em equipe. Cada seção é composta pelos resultados e pela interpretação dos dados coletados. Além de que, foram propostas sugestões de melhorias para os aspectos que se mostraram negativos.

\subsection{Perfil do respondente}

A primeira parte do questionário foi composta por sete (7) perguntas, sendo possível obter uma descrição geral do perfil dos entrevistados.

A pergunta inicial teve o objetivo de identificar a quantidade de colaboradores atuantes nas bibliotecas do CTG e CE. Portanto, constatou-se que dezessete (17), ou seja, 42,5\% pertencem a biblioteca setorial do CE, enquanto vinte e três (23), que corresponde a 57,5\%, trabalham na biblioteca setorial do CTG.

Com o intuito de vislumbrar o perfil do público entrevistado, questionou-se o cargo exercido por estes profissionais em suas referidas unidades de trabalho, assim apresentado no quadro a seguir:

\begin{tabular}{|l|c|c|}
\hline \multicolumn{1}{|c|}{ Cargos efetivos } & $\begin{array}{c}\text { № de funcionários/ Biblioteca } \\
\text { do CTG }\end{array}$ & № de funcionários/ Biblioteca do CE \\
\hline Bibliotecário & 04 & 04 \\
\hline Coordenador/Bibliotecário & 01 & 01 \\
\hline $\begin{array}{l}\text { Assistentes administrativos (profissionais de } \\
\text { nível médio) }\end{array}$ & 01 & 05 \\
\hline $\begin{array}{l}\text { Técnico Administrativo (profissionais de nível } \\
\text { médio) }\end{array}$ & 04 & 01 \\
\hline $\begin{array}{l}\text { Técnico em assuntos educacionais } \\
\text { (profissionais de nível superior, não tem } \\
\text { formação em biblioteconomia) }\end{array}$ & 01 & 01 \\
\hline Servente & 02 & 01 \\
\hline
\end{tabular}




\begin{tabular}{|c|c|c|}
\hline \multicolumn{1}{|c|}{ Cargo transitório: } & № de bolsistas/ Biblioteca do & № de bolsistas/ biblioteca CE \\
\hline $\begin{array}{l}\text { Bolsistas (graduandos de diversas áreas de } \\
\text { formação de nível superior) }\end{array}$ & 10 & 04 \\
\hline Total geral de entrevistados: & 23 & 17 \\
\hline
\end{tabular}

\section{QUADRO 1 - Cargos efetivos e transitórios exercidos nas bibliotecas (continuação)}

Conforme expõe o quadro 1, o maior número de colaboradores concentrados na biblioteca do CTG corresponde a bolsistas, estes exercem suas atividades em quatro horas diárias, se enquadrando na categoria de colaboradores com "cargo transitório" em virtude que o período máximo de atuação nas bibliotecas não pode ultrapassar o limite de dois anos. Em seguida, estão os profissionais bibliotecários que fazem parte do quadro de funcionários efetivos da instituição.

Diferentemente, na biblioteca do CE a maior representatividade de funcionários, correspondendo a cinco (5), consiste em assistentes administrativos, seguidos por bibliotecários que configuram um total de cinco (4) profissionais.

Complementando as informações acerca da unidade de trabalho, indagou-se há quanto tempo estes colaboradores atuam nas bibliotecas. Assim evidenciado no quadro a seguir:

\begin{tabular}{|c|c|c|}
\hline $\begin{array}{c}\text { Tempo de trabalho dos funcionários } \\
\text { efetivos: }\end{array}$ & $\begin{array}{l}\text { № de funcionários / } \\
\text { biblioteca do CTG }\end{array}$ & № de funcionários/ na biblioteca do CE \\
\hline Menos de 6 meses & - & 1 \\
\hline De 6 meses a 5 anos & 7 & 7 \\
\hline De 6 a 10 anos & 4 & 4 \\
\hline De 11 a 15 anos & - & 1 \\
\hline Acima de 15 anos & 2 & - \\
\hline Tempo de trabalho dos bolsistas & $\begin{array}{c}\text { № de bolsistas/ biblioteca } \\
\text { do CTG }\end{array}$ & № de bolsistas/ biblioteca do CE \\
\hline Menos de 6 meses & 6 & 1 \\
\hline De 6 meses a 5 anos & 4 & 3 \\
\hline Total geral de entrevistados: & 23 & 17 \\
\hline
\end{tabular}

QUADRO 2 - Tempo de trabalho dos funcionários efetivos e bolsistas

De acordo com o quadro 2, o maior índice de sete (7) funcionários efetivos, trabalham na biblioteca do CTG entre 6 meses a 5 anos. Na biblioteca do CE o quantitativo mais elevado também aponta para sete (7) funcionários, que atuam na instituição entre 6 meses a 5 anos. Somados aos bolsistas existentes, que pelo cargo exercido trabalham nas bibliotecas até o período máximo de dois anos, depreende-se que em geral, o quadro de colaboradores é relativamente "novo" nas duas instituições.

Apenas uma a pequena parcela de dois (2) funcionários da biblioteca do CTG estão na instituição há mais de 15 anos, o que possibilita considerar que estes, pelo tempo de trabalho exercido, possuem um conhecimento mais aprofundado acerca da estrutura e cultura organizacional presentes na instituição.

Em relação à formação profissional, os funcionários e bolsistas responderam uma questão referente ao nível de formação. O quadro abaixo apresenta os resultados obtidos.

Percebe-se que na biblioteca do CTG o maior índice de respostas aponta para a predominância de colaboradores com o ensino superior em andamento. Este item remete ao quantitativo de bolsistas existentes, que só podem atuar nas bibliotecas sob a condição de estarem cursando regularmente o ensino superior na 
Universidade. Como segunda alternativa mais optada, tem-se a quantidade de seis (6) funcionários com o nível de especialização, um dado importante por revelar que parte significativa dos profissionais procura se qualificar além da graduação.

\begin{tabular}{|l|c|c|}
\hline $\begin{array}{c}\text { Nível de formação profissional dos } \\
\text { funcionários efetivos e de cargo transitório }\end{array}$ & $\begin{array}{c}\text { No de respostas/ } \\
\text { biblioteca do CTG }\end{array}$ & № de respostas/ biblioteca do CE \\
\hline Nível médio completo & 3 & 3 \\
\hline Superior em andamento & 10 & 7 \\
\hline Superior completo & 2 & 2 \\
\hline Especialização & 6 & 4 \\
\hline Mestrado & 2 & 1 \\
\hline Doutorado & - & - \\
\hline Total de entrevistados: & 23 & \\
\hline
\end{tabular}

QUADRO 3 - Nível de formação profissional

Na biblioteca do CE há um índice elevado de colaboradores com o ensino superior em andamento, tanto pela presença de bolsistas, quanto pela iniciativa de alguns assistentes administrativos (que ingressaram na instituição com o ensino médio) em estarem procurando obter uma maior qualificação profissional através do ensino superior. Resultados que em geral são positivos, por refletirem no bom nível de formação profissional do corpo de funcionários atuantes nas duas bibliotecas setoriais.

\subsection{Aspectos: liderança}

Nesta seção, as perguntas foram desenvolvidas com o intuito de conhecer os índices de satisfação ou insatisfação quanto à esfera de liderança nas duas bibliotecas setoriais da UFPE.

Para isto, a primeira pergunta ocupou-se em conhecer o relacionamento de cada funcionário com sua chefia imediata, visando compreender se estes possuem uma relação amigável, de parceria e companheirismo no trabalho, ou se é conflitante, proporcionando sentimentos de insatisfação. Neste sentido, quatro (4) alternativas foram propostas para caracterizar este relacionamento, buscando identificar se é ruim, regular, bom ou ótimo. $\bigcirc$ quadro 4 mostram os índices obtidos:

\begin{tabular}{|c|c|c|c|c|}
\hline $\begin{array}{c}\text { Relacionamento com a chefia imediata/ } \\
\text { funcionários da biblioteca do CE }\end{array}$ & Ruim & Regular & Bom & Ótimo \\
\hline № funcionários & - & - & 9 & $47,06 \%$ \\
\hline \% funcionários & - & - & $52,94 \%$ & Ótimo \\
\hline $\begin{array}{c}\text { Relacionamento com a chefia imediatal } \\
\text { funcionários da biblioteca do CG }\end{array}$ & Ruim & Regular & Bom & 12 \\
\hline № funcionários & - & - & 11 & $52,18 \%$ \\
\hline
\end{tabular}

QUADRO 4 - Relacionamento com a chefia imediata/funcionários da biblioteca do CTG e CE

Como pode ser observado no quadro 4 os níveis de relacionamento com a chefia imediata, na biblioteca do CTG e CE, variaram de "bom" a "ótimo". Nenhum respondente analisou o relacionamento como "ruim" ou "regular". Neste âmbito, entende-se que os funcionários das duas bibliotecas concordam que o relacionamento com a chefia imediata é satisfatório, à medida que não foram apresentados resultados negativos quanto à convivência com seus superiores imediatos no ambiente de trabalho.

Este indicativo já é um bom começo para a determinação de um clima organizacional positivo nessas bibliotecas, tendo em vista que as relações entre líderes e liderados são de extrema importância para o bom 
andamento das atividades propostas pelas instituições e para a manutenção de um ambiente de trabalho harmonioso.

A segunda pergunta quanto ao aspecto liderança, foi direcionada a conhecer se a chefia imediata das bibliotecas é acessível para tratar de assuntos relacionados ao trabalho. Tanto na biblioteca do CTG quanto na biblioteca do CE, todos os respondentes, ou seja, 100\% dos colaboradores, afirmaram que seus chefes são acessíveis para tratar de tais assuntos. Isto significa que os gestores não criam barreiras no momento de falar sobre as rotinas de trabalho, tirar dúvidas e dialogar com os funcionários sobre o trabalho nas bibliotecas.

Relacionada a pergunta anterior, foi questionado se os funcionários sentem liberdade para opinar e expressar suas ideias no ambiente de trabalho e vinte e dois (22) funcionários da biblioteca do CTG sentem esta liberdade. Apenas um (1) colaborador revelou o contrário. Igualmente na biblioteca do CE em que apenas um (1) respondente afirmou não se sentir a vontade para opinar.

É certo que as organizações que dão abertura para ouvir seus funcionários, seja para colher críticas, opiniões, e, sobretudo, ideias, possuem grandes chances de desenvolvimento. Pois, compreende-se que estão sempre em busca de aperfeiçoar suas atividades, inovando, atualizando e buscando minimizar possíveis falhas na prestação de serviços.

Promover reuniões para deixar claro que os funcionários, a qualquer momento, podem opinar e externar suas convicções e ideias visando contribuir com o trabalho na biblioteca, e que dentro das possibilidades as sugestões poderão ser atendidas, é uma boa opção para que os funcionários sintam segurança e liberdade para se expressarem.

$\mathrm{Na}$ intenção de visualizar como os funcionários percebem o estilo de liderança exercido por sua chefia imediata, três (3) opções de estilos de lideranças foram colocados para que pudessem assinalar a que fosse correspondente. No caso, a liderança autocrática, democrática e liberal.

Cada estilo apresentou-se acompanhado de um pequeno texto explicativo para auxiliar os entrevistados no ato da resposta. Ainda foi fornecida a alternativa: "Nenhuma das respostas", para caso necessário, os funcionários pudessem justificar o porquê não acham que a chefia se enquadra em um desses três estilos e falar abertamente como é a liderança exercida.

Vislumbrou-se que tanto na biblioteca do CTG quanto na do CE, nenhum funcionário avaliou seus líderes como "autocráticos" ou "liberais". As opções assinaladas corresponderam à "liderança democrática" ou à "nenhumas das alternativas".

Apenas um (1) respondente de cada unidade entrevistada assinalaram o item "nenhuma das alternativas" e externaram:

\footnotetext{
"O líder fixa as diretrizes, mas da certa autonomia e responsabilidade, dentro de uma liberdade vigiada e monitorada" (Funcionário da biblioteca do CTG)

"Escolhi nenhuma das alternativas por perceber que algumas decisões são mais liberais e outras mais centralizadas" (Funcionário da biblioteca do CE)
}

Dessa forma, para saber se os funcionários estão satisfeitos com o estilo de liderança que assinalaram ou indicaram na questão anterior, foi perguntado se estão satisfeitos ou não. Como resposta, obteve-se o indicador de $100 \%$ dos entrevistados, tanto da biblioteca do CTG, quanto do CE, demonstrando satisfação total com a liderança imediata.

A partir disto, conclui-se que a forma mais maleável de liderar, onde as pessoas podem participar, dialogar e lançar ideias, faz com que os funcionários se agradem do estilo de liderança exercido.

Procurou-se observar também, como os funcionários consideram sua chefia no tocante à liderança. Nas duas bibliotecas prevalece a afirmação de que os líderes estão exercendo sua função com êxito.

Por fim, a última pergunta do tópico liderança foi pensada de uma forma mais abrangente, objetivando conhecer a visão dos funcionários quanto ao modelo de gestão vigente no serviço público, considerando que no senso 
comum predomina-se o excesso de burocracia, a falta de autonomia na tomada de algumas decisões, e a demora na obtenção de recursos para efetivação de melhorias no espaço e outros.

Assim, foi questionado se o estilo vigente tem atrapalhando no desempenho de suas atividades profissionais. Ficou visível que a maior parcela de vinte e um (21) colaboradores da biblioteca do CTG e dezesseis (16) da biblioteca do CE, opinaram que o estilo de gestão vigente no serviço público não tem atrapalhado suas atividades profissionais.

Depreende-se, portanto, que apesar de algumas limitações enfrentadas, da possível demora para que recursos materiais, financeiros e tecnológicos cheguem nas bibliotecas, das hierarquias e burocracias existentes nas instituições públicas, os colaboradores estão conseguindo driblar as dificuldades encontradas.

\subsection{Aspectos: comunicação}

O primeiro questionamento construído em torno do assunto consistiu em identificar se os colaboradores das bibliotecas do CTG e CE acreditam que a gestão das respectivas instituições comunica adequadamente os motivos de suas tomadas de decisões, ou seja, se é notável a preocupação de mantê-los atualizados, bem informados, ou até mesmo, consultá-los quando necessário na busca de opiniões.

Os resultados mostraram que para a maioria dos entrevistados a comunicação é adequada, visto que na biblioteca do CTG, 93,3\% afirmaram que "sim", a gestão comunica as suas decisões adequadamente, enquanto somente 6,7\% afirmaram o contrário. Similarmente, na biblioteca do CE a maioria dos respondentes equivalendo à $88,3 \%$, alegaram que a gestão faz a comunicação adequada de suas decisões. E um menor percentual, de $11,7 \%$, negou.

Acentua-se, portanto, a relevância dos gestores manterem os profissionais informados das decisões tomadas, já que quanto maior for o envolvimento dos colaboradores com a organização, maior será o comprometimento conforme identificado na literatura especializada (MACEDO, 2007).

Atrelada à pergunta anterior, buscou-se verificar por quais meios os funcionários obtêm as informações necessárias acerca do trabalho, a exemplo, dias de reunião, abertura de cursos de capacitação, alterações de expedientes e outras informações.

Nas duas bibliotecas abordadas, há um predomínio de funcionários que obtém informações sobre o trabalho diretamente pela chefia imediata.

É interessante que os líderes, além da comunicação verbal, explorem outros meios de comunicação existentes, como por exemplo, os quadros de aviso, sites e e-mail's, para que a comunicação fique registrada e oficializada, eliminando o surgimento de possíveis rumores e distorções de informações (RIBEIRO, 2004).

Para compreender como o funcionário avalia a comunicação, diálogo, e a troca de informações entre equipes e setores das bibliotecas, tendo em vista que o trabalho nas unidades informacionais funciona de modo cooperativo para que a prestação de serviços possa fluir de maneira produtiva, as respostas evidenciaram que a comunicação entre equipes da biblioteca do CTG varia de "boa" à "ótima".

Já na biblioteca do CE, evidencia-se que a comunicação prevalece como "boa" e "regular", ou seja, os dados já mostram que é preciso melhorar este ponto, tendo em vista que as interações entre os membros não está sendo positiva em sua totalidade.

Infelizmente, em algumas instituições preservam em sua estrutura e cultura organizacional, a ideia que para firmar uma boa comunicação com seus funcionários é suficiente que o líder repasse as atividades que cada um irá desenvolver e todos estarão bem entendidos em seus trabalhos diários.

Entretanto, não basta apenas o líder repassar o que deve fazer, é preciso manter estreita comunicação com suas equipes, e também, estimulá-las a interagirem entre si, buscando compartilharem ideias, opiniões, sugestões, estando em constante troca de informações para evitar falhas na comunicação, perca de tempo com retrabalhos, mal uso de informações distorcidas, evitando dessa forma possíveis conflitos e desentendimentos (CODA, 1997). 
Reservar periodicamente alguns minutos para promover encontros com as equipes de trabalho, elaborar dinâmicas que estimulem a comunicação e interação grupal, fornecer mini-palestras de modo a enfatizar os benefícios da efetiva comunicação no trabalho, dos canais de comunicação existentes, são táticas simples que podem ser empregadas pelos líderes dessas bibliotecas no intuito de reforçar a comunição e o diálogo entre as pessoas no trabalho.

\subsection{Aspecto: motivação}

Visando analisar a satisfação dos funcionários das bibliotecas em relação à motivação no trabalho, buscou-se averiguar se eles sentem-se motivados e reconhecidos pela chefia imediata, objetivando perceber se os líderes tecem elogios, ressaltam a importância do trabalho de cada funcionário, se atribuem o sucesso do alcance de objetivos e metas a cada colaborador que contribuiu com seus esforços etc.

Portanto, nesta questão, 95,6\% dos funcionários da biblioteca do CTG, afirmaram que se sentem motivados e reconhecidos pela chefia imediata, e somente $4,4 \%$, revelaram o contrário.

$\mathrm{Na}$ biblioteca do CE a situação é semelhante, visto que a maioria dos respondentes, equivalendo a $88.3 \%$, responderam estar motivados e reconhecidos, enquanto 11,7\% revelaram não se enquadrar nesta perspectiva.

Existem líderes que possuem a facilidade de criticar os colaboradores quando cometem erros, porém apresentam dificuldades em instruí-los a acertarem e até mesmo a reconhecerem a força de seus acertos. Ter o trabalho reconhecido é uma das maiores expectativas dos funcionários nas organizações, pois este reconhecimento reflete positivamente na auto-estima e na autoconfiança dos mesmos, ocasionando o sentimento de motivação. Por isso este fator deve ser mais observado (SOUZA, 2009).

No escopo de compreender a motivação desses profissionais, foi perguntado se os entrevistados gostam do trabalho que realizam, e se estão motivados a desenvolvê-lo de maneira eficiente. O quadro a seguir retrata os resultados obtidos:

\begin{tabular}{|c|c|c|}
\hline $\begin{array}{c}\text { Você gosta do trabalho que realiza e se sente } \\
\text { motivado para exercê-lo de modo eficiente? }\end{array}$ & $\begin{array}{c}\text { № de respostas/ } \\
\text { biblioteca do CTG }\end{array}$ & № respostas/ biblioteca do CE \\
\hline Sim & 18 & 14 \\
\hline Não & 5 & 3 \\
\hline Total de entrevistados: & $\mathbf{2 3}$ & $\mathbf{1 7}$ \\
\hline
\end{tabular}

QUADRO 5 - Gosto pelo trabalho que realiza

Com base no quadro acima, é notório que nas duas bibliotecas prevalece o número de funcionários que gostam do trabalho que realizam, estando motivados a exercê-lo de maneira eficiente. Estes posicionamentos remetem à motivação e ao reconhecimento profissional que as chefias imediatas procuram fortalecer com seus membros, conforme os próprios funcionários externaram na pergunta anterior.

Todavia, uma menor quantidade de cinco (5) funcionários da biblioteca do CTG e três (3) da biblioteca do CE, apontaram não gostar do trabalho desempenhado. Uma possibilidade que pode justificar estes índices negativos é que a estrutura e cultura organizacional presentes na instituição podem colaborar para que eles não gostem do trabalho realizado, tendo em vista que a cultura dita às normas, regras e maneiras de desenvolver as atividades. Em virtude disto é fundamental que o ambiente de trabalho seja o mais agradável possível, na intenção de minimizar os impactos dessa ausência de gosto pelo trabalho.

Almejando reforçar as percepções em torno da motivação, perguntou-se aos funcionários o principal fator que os motivam a trabalhar na biblioteca. Houve respostas mistas quanto ao principal fator de motivação. No entanto, prevaleceu a "flexibilidade de horário". 
Considerando que os colaboradores conseguem adequar seu tempo, e além de trabalhar, podem estudar e realizar outras atividades de seus interesses, ocasionando um estímulo maior para permanecerem atuando nessas instituições.

Assim, a partir dos questionamentos relacionados à motivação, verifica-se que há uma satisfação predominante quanto a este aspecto. Cabe aos gestores procurar manter esta atmosfera positiva e continuar desenvolvendo ações para que os funcionários se mantenham cada vez mais motivados e comprometidos no trabalho.

\subsection{Aspecto: trabalho em equipe}

Neste item foi realizada uma indagação no sentido de identificar se os colaboradores das bibliotecas do CTG e CE mantêm um bom relacionamento com seus colegas de trabalho, como pode ser visto no quadro a seguir:

\begin{tabular}{|c|c|c|c|}
\hline Pergunta: & Alternativas & $\begin{array}{c}\text { No de respostas/ } \\
\text { biblioteca do CTG }\end{array}$ & $\begin{array}{c}\text { № de respostas/ } \\
\text { biblioteca do CE }\end{array}$ \\
\hline $\begin{array}{c}\text { Você possui uma boa relação com } \\
\text { seus colegas de trabalho? } \\
\text { (Ex: boa comunicação, união, } \\
\text { interação etc) }\end{array}$ & (1) Sim & 22 & 17 \\
\cline { 2 - 4 } & (2) Não & 1 & - \\
\hline
\end{tabular}

QUADRO 6 - Relação entre colaboradores das bibliotecas

Através das respostas obtidas, é compreensível que majoritariamente os colaboradores das bibliotecas supracitadas mantém um bom relacionamento com seus colegas de trabalho. Este indicativo é bastante satisfatório, pela observada importância que o trabalho em equipe exerce dentro desses espaços, no sentido de possibilitar o desempenho cooperativo de atividades, e, além do mais, a troca de experiências, saberes e informações.

Sabe-se que o trabalho em equipe, para ser melhor desempenhado, deve ter o apoio e estímulo da liderança, a quem cabe direcionar, atribuir responsabilidades, motivar e influenciar positivamente os membros. Neste sentido, perguntou-se aos funcionários se os líderes das bibliotecas incentivam o trabalho em equipe, tendo obtidas as seguintes respostas:

\begin{tabular}{|c|c|c|c|}
\hline Pergunta: & Alternativas & $\begin{array}{c}\text { № de respostas/ biblioteca do } \\
\text { CTG }\end{array}$ & $\begin{array}{c}\text { № de respostas/ biblioteca } \\
\text { do CE }\end{array}$ \\
\hline $\begin{array}{c}\text { Em seu local de trabalho, } \\
\text { os líderes incentivam o } \\
\text { trabalho em equipe? }\end{array}$ & (1) Sim & 20 & 12 \\
\cline { 2 - 4 } & (2) Não & 3 & 5 \\
\hline
\end{tabular}

QUADRO 7 - Incentivo ao trabalho em equipe

A partir do quadro 7, é conclusivo que o trabalho em equipe é predominantemente incentivado nesses espaços. Logo, no desígnio de reforçar as percepções em torno do aspecto trabalho em equipe, buscou-se identificar se os funcionários estão conscientes de sua importância. Para isto, foi pedido que indicassem notas de 0 a 10, que correspondessem ao grau de relevância atribuído. O quadro 8 elucidam comparativamente esta questão:

\begin{tabular}{|c|c|c|c|c|c|c|c|c|c|c|}
\hline Biblioteca do CTG & 1 & 2 & 3 & 4 & 5 & 6 & 7 & 8 & 9 & 10 \\
\hline $\begin{array}{c}\text { De 0 à 10, que nota você atribui a } \\
\text { importância da cooperação e do } \\
\text { trabalho em equipe na biblioteca? }\end{array}$ & & & & & & & 1 & 9 & 4 & 9 \\
\hline
\end{tabular}




\begin{tabular}{|c|l|l|l|l|l|l|l|l|l|l|}
\hline Biblioteca do CE & 1 & 2 & 3 & 4 & 5 & 6 & 7 & 8 & 9 & 10 \\
\hline $\begin{array}{c}\text { De 0 à 10, que nota você atribui a } \\
\text { importância da cooperação e do } \\
\text { trabalho em equipe na biblioteca? }\end{array}$ & & & & & & & 3 & 5 & 3 & 6 \\
\hline
\end{tabular}

\section{QUADRO 8 - Grau de importância do trabalho em equipe, apontado pelos funcionários} da biblioteca do CTG e CE (continuação).

Observa-se que o grau de importância quanto ao trabalho em equipe, atribuído por cada funcionário das duas bibliotecas, variou entre as notas 7 a 10. Com isso, fica explícito que os funcionários estão cientes do quanto o trabalho em equipe é importante e necessário dentro de seus espaços de trabalho, onde todos precisam uns dos outros para realizar tarefas e alcançar objetivos e metas.

Assim, diante de todas as considerações em torno do aspecto trabalho em equipe, foi possível observar que as equipes de trabalho possuem boas relações entre si e recebem o apoio e incentivo da liderança, demonstrando que este tipo de trabalho é valorizado nas duas instituições.

\section{Considerações finais}

A partir do levantamento bibliográfico acerca do tema clima organizacional verificou-se na literatura a existência de poucos estudos que o atrela à área de biblioteconomia. Entretanto, torna-se evidente que a pesquisa de clima organizacional como ferramenta de gestão, direciona-se a todas as organizações que procuram desenvolver-se e obter destaque, prezando pelo bem estar das pessoas que atuam em seus espaços.

Dessa forma, compreende-se que a temática também é relevante para as bibliotecas universitárias, tendo em vista que são organizações constituídas por recursos humanos, tecnológicos, materiais, financeiros, que juntos, colaboram para a difusão da informação dentre o público alvo.

Sendo os recursos humanos preponderantes para que obtenham sucesso e atinjam os objetivos desejados. Assim este tipo de pesquisa pode contribuir para a satisfação dos colaboradores, trazendo consigo resultados mais eficazes.

Neste escopo, os dados apurados na pesquisa de clima organizacional realizada nas bibliotecas setoriais do CTG e CE da Universidade Federal de Pernambuco, partiram de questões formuladas no sentido de identificar se o clima organizacional dessas bibliotecas setoriais encontrava-se predominantemente satisfatório ou insatisfatório, buscando identificar melhorias necessárias para um desempenho com excelência do clima organizacional.

Com base nos dados obtidos, evidenciou-se que o clima organizacional presente nessas instituições encontrava-se satisfatório. Todos os aspectos analisados em torno da liderança, comunicação, motivação e trabalho em equipe, mostraram-se propícios a um ambiente de trabalho agradável e motivador.

Portanto, espera-se que as contribuições concedidas no discorrer de cada aspecto analisado, sirvam como base para que os gestores de cada biblioteca possam manter a atmosfera positiva que foi percebida dentre as opiniões de seus funcionários e que os pontos que se mostraram negativos possam ser repensados e consequentemente melhorados. 


\section{Referências}

CAPEZIO, Peter. Como ser uma equipe de sucesso. São Paulo: Marker Book, 1999.

CARVALHO, Karina M. Uma análise do clima organizacional em uma empresa varejista de móveis e eletros na cidade de picos - PI. 2011. 99p. Monografia (Graduação em Administração) - Universidade Federal do Piauí, Picos PI.

CHIAVENATO, Idalberto. As organizações e sua administração. In: sucesso nas organizações. 3 reimp. Rio de Janeiro: Elsevier, 2010. p. 59-183

Clima organizacional e cultura organizacional. In: Introdução à teoria geral da administração: uma visão abrangente da moderna administração das organizações. 3 ed. Rio de Janeiro: Elsevier, 2004. p. 296-298.

Conceito de organização. In: Comportamento organizacional: A dinâmica do sucesso nas organizações. 3 reimp. Rio de Janeiro: Elsevier, 2010. p. 24-34.

Liderança. In: Introdução à teoria geral da administração: uma visão abrangente da moderna administração das organizações. 3 ed. Rio de Janeiro: Elsevier, 2004. p. 100-104.

CODA, Roberto. Pesquisa de clima organizacional e gestão estratégica de recursos humanos. In: BERGAMINI, Cecília Whitaker; CODA, Roberto. Psicodinâmica da vida organizacional: Motivação e Liderança. 2. Ed. São Paulo: Atlas, 1997. p. 94-107.

FALCÃO. Zizete. A importância na interação entre pessoas e organizações. 2010. Disponível em: <http://www.administradores.com.br/artigos/carreira/a-importancia-na-interacao-entre-pessoas-e-organizacoes/47977/>. Acesso em: 27 de Dezembro de 2013.

FELDHAUS, Solange Ines. O clima organizacional no quadro de pessoal atuante nas bibliotecas da Universidade do Contestado. Florianópolis: UDESC, 2005. Dissertação de Mestrado. Disponível em: <http://www.pergamumweb.udesc.br/dados-bu/000000/000000000001/000001C3.pdf>. Acesso em: 2 setembro de 2013.

GIL, Antônio Carlos. Gestão de pessoas: enfoque nos papéis profissionais. São Paulo: Atlas, 2001.

LUZ, R. Gestão do clima organizacional. Rio de Janeiro: Qualitymark Editora LTDA, 2012.

MACEDO, Ivanildo Izaias et al. Aspectos comportamentais da gestão de pessoas. Rio de Janeiro: Editora FGV, 2007

MAXIMIANO, Antonio Cesar Amauru. Clima organizacional e Desempenho. In: . Teoria geral da administração: da escola cientifica à competitividade em economia globalizada. São Paulo: Atlas, 1997. p.168-169.

PRADO, Noêmia Schoffen; ABREU, Juliana de. Modelos de organização e gestão das bibliotecas universitárias do estado de Santa Catarina. Revista ACB: Biblioteconomia em Santa Catarina, Florianópolis, v. 10, n. 1, p. 107-123, 2005.

RIBEIRO, Rejane Maria Rosa. Motivação dos recursos humanos em bibliotecas universitárias. Revista Digital de Biblioteconomia \& Ciência da Informação, Campinas, v. 2, n. 1, p. 71-79, jul./dez. 2004.

SILVA, Neli Terezinha da. Clima organizacional: Uma proposta dos fatores a serem utilizados para avaliação do clima de uma instituição de ensino superior. Dissertação (Mestrado). Santa Catarina, 2003. Disponível em: <https://repositorio.ufsc.br/xmlui/bitstream/handle/123456789/85479/223610.pdf?sequence=1>. Acesso em: 12 de Setembro de 2013.

SILVEIRA, Júlia Gonçalves da. Gestão de recursos humanos em bibliotecas universitárias: reflexões. Ciência da Informação, Brasília, v. 38, n. 2, p. 126-141, maio/ago. 2009.

SOTO, Eduardo. A mudança na estrutura organizacional. In: SOTO, Eduardo. Comportamento organizacional: o impacto das emoções. São Paulo: Pioneira Thompson Learning, 2002. p 256-261

SOUZA, Bruno Rodrigo de, et al. Comunicação organizacional: A importância da comunicação nas organizações. 2009. Disponível em: <http://www.fatesc.edu.br/wpcontent/blogs. dir/3/files/pdf/tccs/a importancia da comunicacao nas organizacoes.pdf >. Acesso em: 10 set 2013 


\title{
Dados dos autores
}

\author{
Andréa Maria da Silva \\ Bacharel em Biblioteconomia pela Universidade Federal de Pernambuco. \\ andrea.dea.54@gmail.com
}

\section{Alexander Willian Azevedo}

Bacharel em Ciência da Informação com habilitação em Biblioteconomia pela Pontifícia Universidade Católica de Campinas. Mestre em Ciência da Informação pelo Programa de Pós-Graduação do Centro de Ciências Humanas e Sociais Aplicadas, PUC-Campinas, Bolsista CAPES. Professor Assistente vinculado ao Departamento de Ciência da Informação da Universidade Federal de Pernambuco (UFPE). Áreas de interesse: Gestão de Unidades de Informação, Inteligência Competitiva, Competência Informacional, Educação.

alexander.azevedo@ufpe.br

\section{Fabio Assis Pinho}

Professor Adjunto do Departamento de Ciência da Informação, atuando nos cursos de Graduação em Biblioteconomia, em Gestão da Informação e no Programa de Pós-Graduação em Ciência da Informação (Mestrado Acadêmico) da Universidade Federal de Pernambuco. Possui Graduação (2002) em Biblioteconomia e Ciência da Informação pela Universidade Federal de São Carlos, Mestrado (2006) e Doutorado (2010) em Ciência da Informação pela Universidade Estadual Paulista Júlio de Mesquita Filho. Foi Subchefe (2009-2011) e Chefe (2011-2013) de Departamento. É Líder do Grupo de Pesquisa: Organização e Representação do Conhecimento, Conselheiro Fiscal da ISKO International Society for Knowledge Organization (Brasil), Vice Coordenador do GT2 da ANCIB, Editor Geral da IRIS - Revista de Informação, Memória e Tecnologia e Coordenador do Programa de Pós-Graduação em Ciência da Informação da UFPE. Tem interesse nas linhas de pesquisa de Organização e Representação do Conhecimento e Memória da Informação Científica e Tecnológica.

fabiopinho@ufpe.br

Recebido - Received: 2015-04-27

Aceitado - Accepted: 2015-09-19

\section{$(\mathrm{cc}) \mathrm{Br}$}

This work is licensed under a Creative Commons Attribution 4.0

United States License.

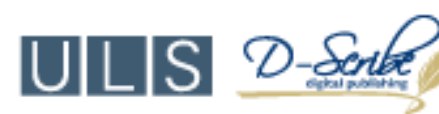

This journal is published by the University Library System of the University of Pittsburgh as part of its D-Scribe Digital Publishing Program and is cosponsored by the University of Pittsburgh Press. 